\title{
The impact of a curriculum course on pre-service primary teachers' science content knowledge and attitudes towards teaching science
}

\author{
Clíona Murphy* and Greg Smith ${ }^{\mathrm{b}}$ \\ ${ }^{a}$ Centre for the Advancement of Science and Mathematics Teaching and Learning (CASTeL), \\ St Patrick's College, Dublin, Ireland; 'bducation Department, National University of Ireland, \\ Maynooth, Ireland
}

\begin{abstract}
Many primary school teachers have insufficient content and pedagogical knowledge of science. This lack of knowledge can often lead to a lack of confidence and competence in teaching science. This article explores the impact of a year-long science methodology (curriculum science) course on second year Bachelor of Education (BEd) students' conceptual and pedagogical knowledge of science and on their attitudes towards teaching science in the primary classroom. A questionnaire, containing closed and open questions, was administered to students at the beginning and end of their science methodology course. The findings revealed that the science course had a positive impact on developing students' scientific content knowledge. While the students were positive about the prospect of teaching science, insufficient scientific content knowledge was a concern for many of them, as were concerns over various teaching methodologies and classroom management issues in teaching science. The findings of this study are worrying, as it is likely that high percentages of these students will enter the teaching profession with similar inaccurate conceptions of science as the students they will be teaching.
\end{abstract}

Keywords: primary science; initial teacher education; science conceptual knowledge; attitudes towards science

\section{Introduction}

Concerns have been expressed nationally and internationally regarding the teaching of primary science. Such concerns centre on: insufficient time in the curriculum being devoted to hands-on investigative approaches to science; teachers' lack of competence and confidence in employing inquiry-based approaches to science; teachers' lack of scientific content knowledge; insufficient practical professional development courses for teachers; and concerns regarding initial teacher education courses in science (De Boo and Randal 2001; Goodrum, Hackling, and Rennie 2000; Jarvis and Pell 2004; OFSTED 2004; Murphy, Neil, and Beggs 2007; Osborne and Simon 1996; Varley, Murphy, and Veale 2008; Waldron et al. 2007; Wellcome Trust 2005).

In Ireland, in response to, and in a bid to address, some of these concerns, science curricula at primary and post-primary levels were reviewed and developed. At postprimary level, a revised junior cycle science curriculum was introduced in 2003, which included a stronger emphasis on practical work (DES 2003). This revised syllabus differs from its predecessor in a number of ways, including reduced length,

*Corresponding author. Email: cliona.murphy@spd.dcu.ie 
and increased emphasis on scientific investigation and on understanding the scientific concepts involved. For the first time ever, a significant element of coursework is based on the students' performance on practical elements of the course in addition to a terminal examination paper. It is hoped that this revised science syllabus will increase interest in science amongst students - leading to an increase in the uptake of science subjects at senior cycle level and third level (DES 2003, 3). The three senior cycle science syllabi have recently been reviewed (NCCA 2011). According to the NCCA, the content of the syllabi will be described in terms of learning outcomes rather than a list of what students should know and there will be an assessment component for practical work.

At primary level, the 1999 science curriculum (DES 1999) has been formally implemented in schools since 2003. This curriculum includes science as a compulsory subject for all primary school students. It embraces the development of concepts and skills, which are to be introduced simultaneously. The curriculum encourages the employment of a variety of teaching approaches and methodologies and also places an emphasis on 'hands-on' classroom science. All primary teachers are expected to contribute to teaching science regardless of their level of interest or qualification in science. The Department of Education and Science (DES) has provided in-service courses (two curriculum days for teachers), which were followed by support through the Primary Curriculum Support Project (PSCP) and the Primary Professional Development Support (PPDS) for qualified primary teachers.

Colleges of education at primary level in the Republic of Ireland require all students to complete courses relating to primary science. Even though the content and time given over to curriculum science varies from college to college, all place a strong emphasis on:

e developing students' pedagogical knowledge in science;

e providing students with the opportunities to become familiar with a range of methodologies in the teaching of science, with particular emphasis on science as a skill-based process and on developing an active learning environment; and

e familiarising students with children's scientific understanding and common alternative conceptions in the context of their cognitive development (Waldron et al. 2009).

Few would disagree with the contention that teachers need to have a good understanding of their subject matter if they are to teach that subject well. However, more than two decades of research on primary school teachers' knowledge of science shows that a considerable number of them lack the required content knowledge and pedagogical understanding to teach science to their students (Appleton and Kindt 1999; Kennedy 1998; Loucks-Horsley et al. 1998; Jarvis and Pell 2004; Murphy, Neil, and Beggs 2007; OFSTED 2004).

There is a considerable amount of research that shows primary teachers' understanding of key science concepts often differs from the generally accepted scientific viewpoint (Kruger and Summers 1988; Harlen and Holroyd 1997). Kruger and Summers conducted a longitudinal study on primary teachers' ideas about forces and energy. They reported that teachers held misconceptions regarding science concepts and that these had common characteristics with those of children. In a research study with 57 primary teachers in Scotland, Harlen and Holroyd (1997) 
found that inadequate science knowledge was a significant factor influencing primary teachers' confidence in teaching science. Poor scientific content knowledge amongst teachers leading to a lack of confidence and perceived competence in teaching science appears to be a world-wide concern (Rennie, Goodrum, and Hackling 2001; Murphy, Neil, and Beggs 2007; Osborne and Simon 1996; OFSTED 2004; Wellcome Trust 2005).

Many primary teachers indicate science as the subject area they least enjoy teaching, because they have little confidence in their science content knowledge and are afraid their classroom teaching/learning activities will yield results they do not understand and cannot explain to students (MacDonald and Sherman 2007). This lack of depth of subject matter knowledge can affect the ability of a teacher to ask appropriate and meaningful questions. McDiarmid, Ball, and Anderson $(1989,198)$ suggest that 'teachers' capacity to pose questions, select a task, and evaluate their pupils' understanding all depend on how they themselves understand the subject matter'. Osborne and Simon $(1996,101)$ similarly state that 'the difficulties caused by teacher subject knowledge may be the rock on which primary science education may founder'.

A number of studies (Kruger and Summers 1988; Harlen and Holroyd 1997; Jarvis and Pell 2004) show primary teachers' understanding of key science concepts often differs from the generally accepted scientific standpoint. Many of their ideas are very similar to the 'misconceptions' or 'alternative conceptions' commonly recognised in children (Driver 1983). They may develop these 'alternative ideas' for several reasons, including the failure to understand the science they were taught at school or exposure to poor teaching of these concepts. It is apparent from the existing literature that students entering initial teacher education colleges hold 'misconceptions' about important science concepts that are essential to their classroom practice. Addressing pre-service teachers' inaccurate understanding of science concepts is therefore essential. If teachers have restricted science knowledge, they are not likely to be aware of children's alternative conceptions and are therefore unlikely to present their students with scientifically accepted explanations. They are likely to give misleading information in an effort to explain science to their students and their own alternative conceptions might impede their students' understanding (Osborne and Simon 1996). Therefore, an important purpose of pre-service science courses must be enhancing teachers' science knowledge. Indeed, Jarvis and Pell's (2004) study revealed that after a year-long intensive in-service programme, while some teachers still held some misconceptions, overall there was a significant improvement in the teachers' scientific conceptions of forces, electricity and changes of state (Jarvis and Pell 2004). However, good knowledge of scientific concepts is not the only prerequisite for successful science teaching.

We would agree with a number of commentators (Simpson and Oliver 1990; Jarvis and Pell 2004; Rennie, Goodrum, and Hackling 2001; Waldron et al. 2009) in arguing that if pre-service science courses are to enhance primary science teaching and learning, other factors besides subject knowledge need to be considered. These include teachers' attitudes to the subject; ability to select appropriate and enjoyable experiences for their students; ability to connect one area of subject learning with others; and interactions with students in the lesson, including identifying 'misconceptions' and providing appropriate explanations. In this context, pedagogical content knowledge has been identified as a crucial element. 
Simpson and Oliver (1990) have argued that, if primary teachers as a group are not as interested in teaching science as they are other subjects, it is likely that students will not experience an adequate background in science during critical stages of their learning. Rennie, Goodrum, and Hackling (2001) found that teachers' attitudes and behaviours in relation to science affect their classroom practice and have a critical influence on the attitudes of their students. Jarvis and Pell's (2004) study also found that a year-long professional development course that addressed teachers' pedagogical and scientific content on a limited number of science topics led to a significant increase in teachers' confidence and attitudes towards teaching science (Jarvis and Pell 2004). Such key factors need to be taken into consideration when planning for effective courses in primary science teaching.

The Irish Association of Social, Scientific and Environmental Education (IASSEE) conducted an all-Ireland longitudinal study that explored a number of avenues regarding initial teacher education in history, geography and science education. Numerous findings emerged from this detailed report (Waldron et al. 2009). However, for the purpose of this paper a brief reference to some of the key findings relating to science in initial teacher education in Ireland is provided.

The findings of the aforementioned study revealed that the majority of student teachers from Northern Ireland and the Republic of Ireland held positive attitudes towards science, felt confident about teaching science, and maintained that science was an important subject for children to learn (Waldron et al. 2009). The vast majority of these students gave positive responses regarding their experiences of teaching science during teaching practice. Reported positive experiences included their interactions with pupils, particular topics they taught and methodologies they employed to teach science. Some of the negative experiences the students reported regarding teaching practice related to classroom management issues and access to sufficient resources. Waldron and colleagues (2009) did not examine the impact of initial teacher education courses in science on student teachers' scientific content knowledge, nor were findings regarding students' concerns regarding teaching science on leaving initial teacher education presented in the report.

Taking into consideration the findings from the Waldron et al. (2009) study, the current study aimed at establishing the extent to which a year-long curriculum science course influenced second year BEd student teachers' conceptual and pedagogical knowledge of science and impacted on their attitudes towards teaching science in the primary classroom. It is hoped that the findings from this study will inform the development of future curriculum science courses at pre-service level.

\section{Methodology}

The present study examined the following questions:

e What scientific qualifications do BEd students have on entering third-level education?

e To what extent do BEd student teachers' scientific concepts develop as a result of the curriculum science course?

e What changes occur in BEd students' attitudes towards teaching science as a result of the curriculum science course? 
e What concerns do BEd students hold regarding the teaching of primary science?

To address these research questions, a survey was conducted with second year Bachelor of Education (BEd) students in one of the education colleges in the Republic of Ireland. A questionnaire was administered to students prior to, and at the end of, their second year curriculum science programme. The initial questionnaire was completed by 333 students while 151 completed the exit questionnaire. The questionnaires were piloted with first year BEd students and adjustments and repiloting were undertaken to ensure acceptable content validity.

The questionnaire contained a number of open-ended and closed questions (see Appendix A). The first section of the questionnaire asked for contextual information regarding the sex of the student teachers and their academic qualifications in science at post-primary and tertiary levels. The second section contained closed and openended questions that were aimed at establishing the students' attitudes towards teaching science. The final section contained statements regarding different aspects of physics and biology. Statements were chosen that were related to learning objectives from different strand units in the primary science curriculum (DES 1999) and that were representative of some of the commonly held 'alternative conceptions' about science (Driver 1983; Summers and Kruger 1992; Smith and Peacock 1992; Jarvis and Pell 2004). The aim of these closed questions was to establish the student teachers' scientific content knowledge.

To facilitate analysis, the data obtained from the closed questions on the questionnaires were entered into Statistical Package for the Social Sciences (SPSS) version 14.0. The measurement of the data from the open-ended questionnaires consisted of responses to be categorised. The 'rules for inclusion' (Lincoln and Guba 1985), that is, the justification for allocating responses to certain categories, were devised when unitising ('coding') the data and these informed discussions surrounding data that could not be unequivocally categorised by the raters. Thus open-ended responses were 'coded' numerically and were then input into SPSS version 14.0.

As 151 students responded in the exit questionnaire as opposed to 333 in the initial questionnaire, the decision was made to take a 50\% random sample of the first dataset to examine the extent to which this would result in substantially different findings from the first administration. This analysis indicated that for each question this 50\% sample resulted in responses that were within $2-3 \%$ of the original findings. A second and third check of the data using different $50 \%$ random samples had similar outcomes. This provides some evidence supporting the conclusion of lack of nonresponse bias in the second administration. The data were also checked for gender non-response bias. This analysis revealed that the percentage of male respondents was similar in both initial and exit questionnaires (11\% and $15 \%$, respectively), providing evidence of lack of non-response bias in gender at the exit stage.

\section{Findings}

Qualifications

A questionnaire was administered to the students at the beginning and end of their curriculum science course. In the initial questionnaire the students were asked to 
record what science subjects they had taken to Leaving Certificate level. A summary of these percentages is provided in Figure 1.

Figure 1 indicates that a considerably higher percentage of students took biology to Leaving Certificate than all other science subjects. Low percentages of students took chemistry (17\%) and only $8 \%$ of students took physics to Leaving Certificate level.

All of these second year BEd students were obliged to take a 48-hour long curriculum science course. However, this course predominantly focuses on the development of the students' pedagogical knowledge rather than on their own scientific content knowledge. The course provides students with the opportunity to use a range of methodologies in the teaching of science with particular emphasis on science as a skill-based process and on an active learning environment. The course is also aimed at familiarising students with children's scientific understanding and common alternative conceptions in the context of their cognitive development. To some extent the course is aimed at developing the students' conceptual knowledge and process skills, however, it is predominantly a pedagogical course (from 'Science Curriculum Course Outline', St. Patrick’s College, Dublin, Ireland, 2010).

When these students graduate they will be obliged to teach the primary science curriculum, which encompasses aspects of physics, chemistry and biology. We would question, therefore, whether they have sufficient scientific background knowledge to competently implement the science curriculum as the curriculum science courses have a considerably stronger emphasis on pedagogy rather than on scientific content knowledge. This concern is further exacerbated by the fact that $33 \%$ of them do not have biology to Leaving Certificate and $83 \%$ and 92\%, respectively, have not taken chemistry or physics to Leaving Certificate level.

\section{Content knowledge}

In a bid to assess whether the curriculum science course had a positive impact on the development of these student teachers' scientific content knowledge, they were probed using a series of questions (see Appendix A) on their ideas about key science concepts found in the primary science curriculum (DES 1999). This was to discover whether or not they held 'inaccurate conceptions' ('misconceptions') regarding key science concepts. 'Inaccurate conceptions' identified in previous research amongst student teachers were incorporated into the questionnaire (Driver et al. 1985; Matthews and McKenna 1996). The questions utilised were adapted from Matthews and McKenna's (1996) study of student primary teachers' understanding of basic science concepts.
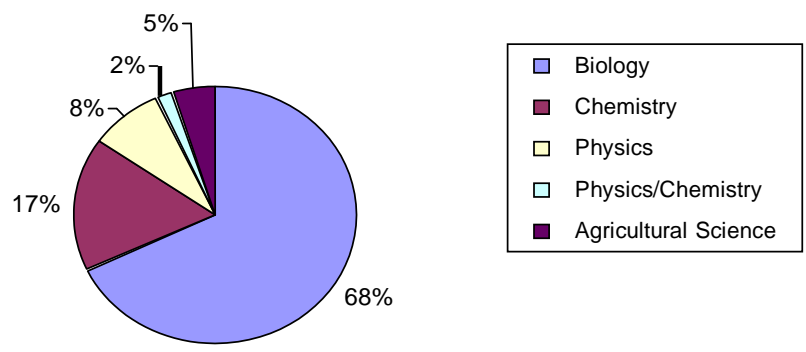

Figure 1. Percentage of students taking science subjects to Leaving Certificate. 
The questions were adapted to take account of the focus of the current study and to ensure compatibility with the requirements of the primary science curriculum.

The chosen statements were related to the Energy and Forces and Living Things strands of the primary science curriculum (DES 1999). We would argue that if teachers are to be competent in teaching these strand units, they should have sufficient scientific conceptual understanding. Tables 1 and 2 provide a summary of the different statements related to aspects of scientific content knowledge, and the percentage of students who responded correctly to each statement at the initial and exit stages.

A very high percentage of students revealed inaccurate understandings of concepts relating to forces and electricity (Table 1). In the initial questionnaire, $67 \%$ of the students revealed inaccurate conceptions regarding friction and floating and sinking, 62\% gave incorrect responses regarding gravity and weight, and 55\% revealed inaccurate understandings of electricity concepts. Although lower percentages of students gave incorrect responses regarding light, heat and sound, $40 \%$ of the respondents maintained that the moon was a light source, $19 \%$ thought sound only travels through air and 37\% believed heat travels from a cold to a hot body.

For the most part, higher percentages of students responded correctly to the statements on plants and animals in the initial and exit questionnaires (Table 2). This is perhaps not surprising, as a considerably higher percentage of these students had taken biology to Leaving Certificate. However, it is still a matter of concern that their responses in the initial questionnaires revealed that $39 \%$ of these student teachers did not know a potato was a plant, and 58\%,66\% and 65\% of them, respectively, did not know that a fish, a fly and a spider were animals.

Table 1. Statements relating to strand: Energy and Forces.

\begin{tabular}{lcc}
\hline Statement (True or false) & $\begin{array}{c}\text { \% Correct Initial } \\
\text { questionnaire }\end{array}$ & $\begin{array}{c}\text { \% Correct Exit } \\
\text { questionnaire }\end{array}$ \\
\hline $\begin{array}{l}\text { Gravity only acts on objects when they are } \\
\text { falling }\end{array}$ & 94 & 96 \\
$\begin{array}{l}\text { Friction only acts on moving objects } \\
\text { Heavy things fall to the ground quicker than }\end{array}$ & 33 & 75 \\
$\quad$ light things & 89 & 95 \\
Objects which are sitting still have no forces & & 69 \\
$\quad$ activity on them & 60 & 95 \\
The moon is luminous & 81 & 68 \\
Sound can only travel through air, not solid or & 45 & 77 \\
$\quad$ liquid & & \\
Less current returns to the battery when it & 63 & 82 \\
$\quad$ passes through say a bulb (it is used up) & & 58 \\
Current flows from battery to bulb but not & 82 & 74 \\
$\quad$ from bulb back to battery & 33 & 76 \\
If an object is at rest no forces are acting on it & 67 & 83 \\
Wood floats and metal sinks & 63 & \\
All metals are attracted to a magnet & 78 & \\
Heat travels from a cold body to a hot body & & \\
If two objects have the same temperature they & &
\end{tabular}


Table 2. Statements relating to strand: Living Things.

\begin{tabular}{lcc}
\hline $\begin{array}{l}\text { Living Things (Plants) Which of the } \\
\text { following are plants? (Tick) }\end{array}$ & $\begin{array}{c}\text { \% Correct Initial } \\
\text { questionnaire }\end{array}$ & $\begin{array}{c}\text { \% Correct Exit } \\
\text { questionnaire }\end{array}$ \\
\hline A tree in the ground & 73 & 88 \\
A potato growing in the ground & 61 & 80 \\
A thistle growing in the ground & 68 & 80 \\
A daisy growing in the ground & 72 & 84 \\
Living Things (Animals) & \% Correct Initial & \% Correct Exit \\
Which of the following are animals? & questionnaire & questionnaire \\
$\quad$ (Tick) & 42 & 64 \\
A fish in a pond & 90 & 95 \\
A dog found around the house & 56 & 73 \\
A human being & 34 & 61 \\
A common household fly & 86 & 94 \\
An elephant & 59 & 71 \\
A snake & 35 & 62 \\
A spider & &
\end{tabular}

These findings point to a lack of fundamental understanding of electricity and forces on the part of the students. This concurs with the views put forward by Jarvis and Pell (2004), namely, that science concepts such as electricity and forces are abstract and are particularly difficult for primary teachers to grasp. Furthermore, they stressed that many teachers appeared to hold 'misconceptions' typically held by children in these content areas. Reasons for this could include emphasis on recall at junior and senior cycle and not focusing on overcoming any such misconceptions students might possess.

On a more positive note, it was apparent from the questionnaires that there was an increase in these BEd students' scientific content knowledge at the exit stage. A higher percentage of students recorded the correct answer in all of the scientific statements at the exit stage. Tables 1 and 2 provide a comparison of the percentages of students who recorded correct responses in the initial and exit questionnaires. It would appear, therefore, that the curriculum science programme had a positive impact on the development of more accurate scientific concepts amongst this cohort of students.

However, while these results are encouraging, a note of caution is advisable. There is still a high proportion of these students who revealed inaccurate understandings of aspects of the Energy and Forces and Living Things strands of the primary science curriculum (DES 1999). This is the only compulsory science course on this three year BEd degree and therefore the vast majority of these students will not engage with formal science education again prior to entering the teaching profession. The findings of the current study are similar to the findings of other international studies cited earlier (Jarvis and Pell 2004; Kruger and Summers 1988; OFSTED 2004; Rennie, Goodrum, and Hackling 2001; Wellcome Trust 2005) in that they appear to indicate that many of this cohort of student teachers still hold similar 'inaccurate conceptions' as the children they may be teaching in the future.

We share concerns expressed by other researchers (Osborne and Simon 1996; McDiarmid, Ball, and Anderson 1989) that, as a result of holding inadequate 
scientific conceptions, these Irish pre-service teachers may provide their future pupils with misleading information in explaining science and their ability to address and challenge their pupils' 'alternative conceptions' could be inhibited. We would question whether these student teachers are sufficiently competent to implement the primary science curriculum.

Attitudes towards teaching science

Section B of the questionnaire was aimed at finding out the students' attitudes towards science. There were four Likert-type questions, with a five-point scale, that were aimed at establishing the students' attitudes towards science. For the first two of these questions the students were asked to state whether they agreed or disagreed with the statements regarding science $(1=$ strongly agree, $5=$ strongly disagree). The two statements were: 'I like science' and 'I think science is an important subject for primary children'. Figures 2 and 3 provide an overview of student responses to each of these questions in the initial and exit questionnaires.

Figures 2 and 3 illustrate that a higher percentage of students gave ratings of 1 ('strongly agree') or 2 ('agree') to the statements 'I like science' and 'I think science is important' in the exit questionnaire. This would appear to indicate that the students held more positive attitudes towards science and the importance of school science after they had taken the curriculum science course.

The third of these Likert-type questions asked the students to rate their confidence regarding teaching science $(1=$ least confident and $5=$ most confident). A higher percentage of students rated responses as 4 ('confident') or 5 ('most confident') in the exit questionnaire (Figure 4). In the initial questionnaire, $40 \%$ and $13 \%$, respectively, gave a 4 or 5 rating to the statement ' $I$ feel confident about teaching science'. The percentages of students giving a 4 or 5 rating to this statement in the exit questionnaire rose to $45 \%$ and $21 \%$, respectively. While these results indicate a rise in students' confidence towards teaching science at the exit stage, they do not reveal a statistically significant increase in confidence (Figure 4).

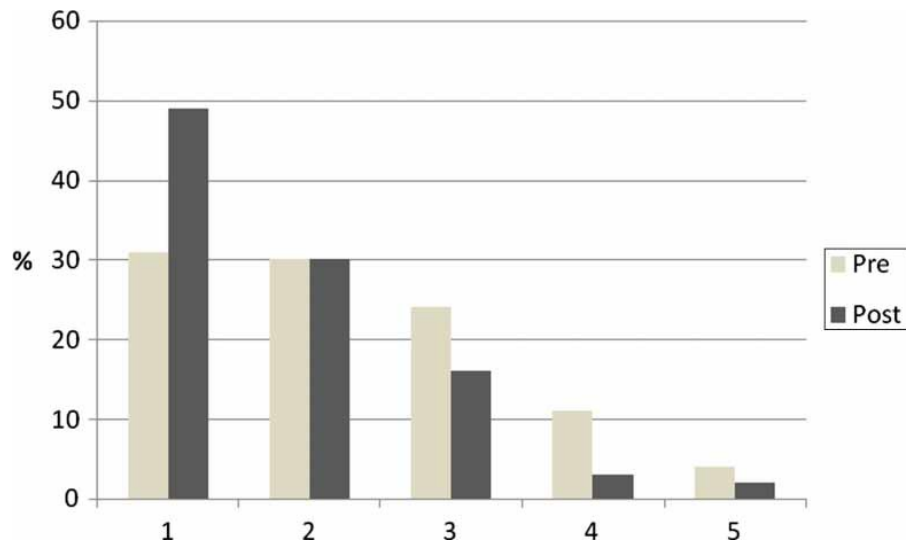

Figure 2. Initial/exit questionnaire: I like science. Note: $1=$ strongly agree, $5=$ strongly disagree. 


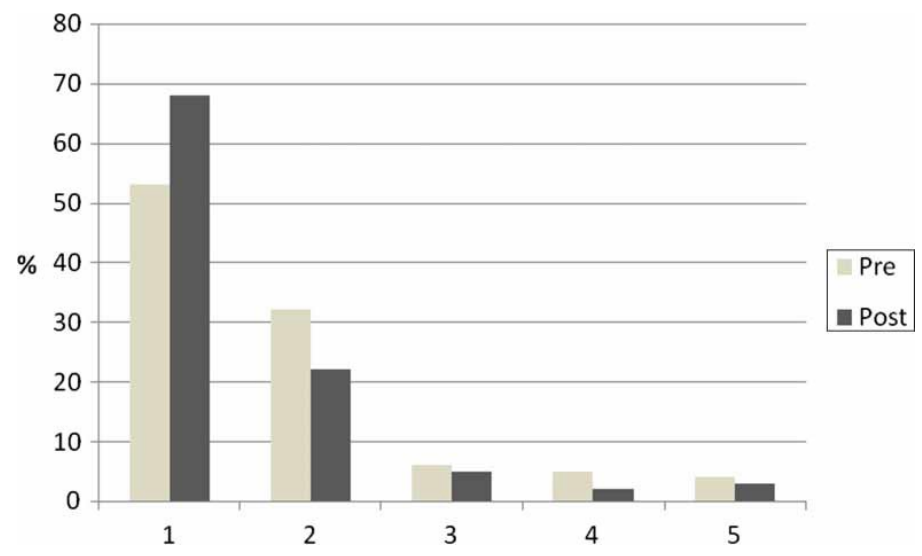

Figure 3. Initial/exit questionnaire: I think science is an important subject.

Note: $1=$ strongly agree, $5=$ strongly disagree.

Concerns regarding teaching science

One of the open-ended questions on the initial and exit questionnaires asked the students to reflect on their concerns pertaining to the teaching of science. Four areas of concern emerged when these questions were analysed.

(1) Scientific content knowledge: students' responses relating to scientific content knowledge in the three science subjects were recorded in this category.

(2) Pedagogical knowledge: concerns pertaining to particular teaching methodologies and teaching and learning related issues were recorded here. Typically the students revealed concerns regarding how to make science fun and interesting; planning activities; hoping experiments 'went to plan'; not having a sufficient bank of activities to teach aspects of the curriculum; and explaining concepts to children in a manner in which they will understand.

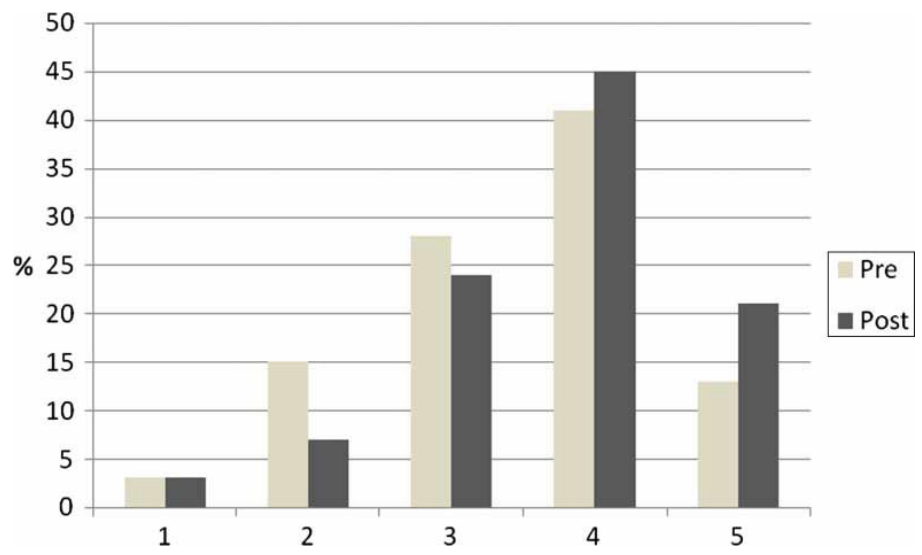

Figure 4. Initial/exit questionnaire: I feel confident about teaching science. Note: $1=$ least confident and $5=$ most confident. 
(3) Classroom management: typically the concerns the students held regarding classroom management issues included: large class sizes in relation to discipline issues, the management of practical work and safety concerns.

(4) Resources: typical concerns reported in this category related to whether or not schools would have sufficient resources to facilitate their science lessons.

Figures 5 and 6 provide a summary of the percentages of students who responded in each of the four categories.

Figure 5 illustrates that the students revealed more concerns about their scientific content knowledge in the areas of physics and biology at the end of the course than at the beginning. Lower percentages of students expressed concerns regarding their knowledge of chemistry at the exit stage. Typically concerns were raised regarding the difficulty they had understanding some of the scientific terminology and many indicated that they felt they had insufficient knowledge to teach older classes in primary school.

Others were anxious because they felt that they themselves held scientific misconceptions. Some of the students expressed concerns about not being able to answer children's questions while others were apprehensive that they might provide children with inaccurate information and perhaps reinforce the children's misconceptions. Others reflected on their pupils' learning and were perturbed at how they might facilitate group work to ensure genuine learning would occur. The following comments succinctly sum up their general concerns here:

Misconceptions I may have myself.

... That I won't be able to answer questions that the children have and I'm concerned about teaching topics like electricity or magnetism.

Having enough knowledge of the topic myself to help change the children's misconceptions.

I would still struggle perhaps with teaching areas such as electricity for example. This is because I myself struggle with understanding the topic and wouldn't be overly confident as a result of this.

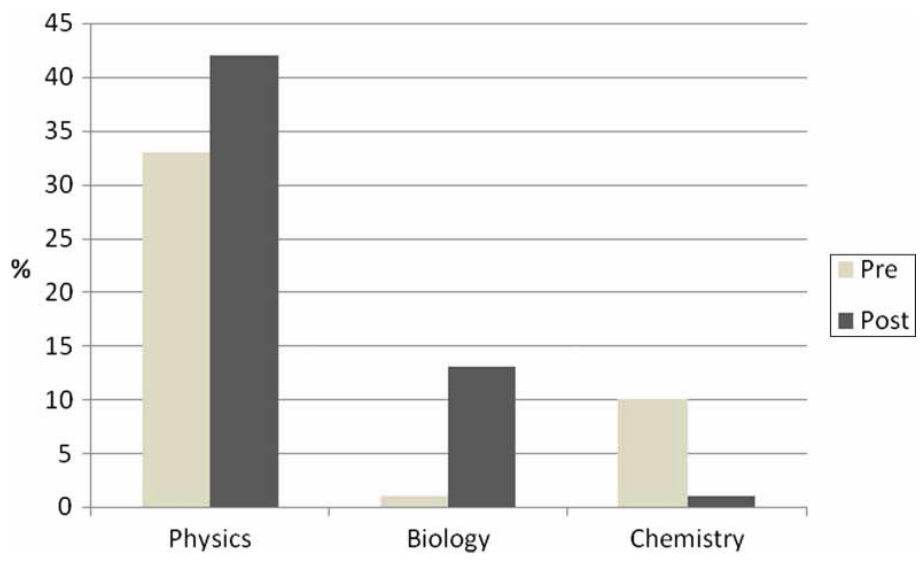

Figure 5. Concerns regarding scientific content knowledge (initial/exit). 


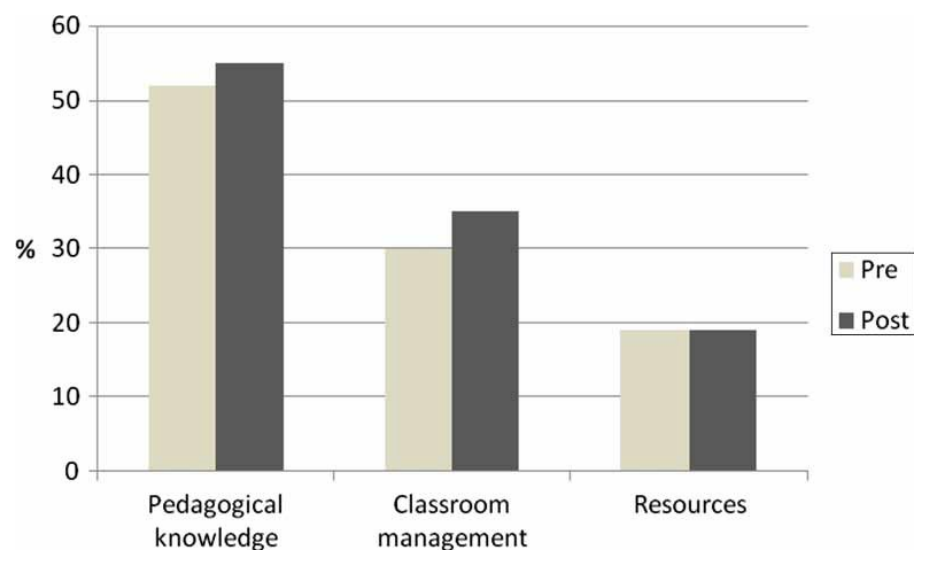

Figure 6. Concerns regarding teaching science (initial/exit).

If an experiment goes wrong, I won't know what the reason is. Sometimes I don't understand the content especially when it comes to things like levers and pulleys.

How to organise the lesson so that the children actually benefit from it.

That the children won't just do the experiments blindly that they will actually learn from them.

Figure 6 reveals that in the exit questionnaire higher percentages of students held concerns about pedagogical knowledge and classroom management than they had before they started the course. The same percentage of students (19\%) reported concerns regarding resources in both initial and exit questionnaires. In relation to the pedagogical knowledge category, some of the students were apprehensive about their ability to challenge children's misconceptions and to provide future pupils with sufficient opportunities to address and develop their ideas:

Some children understanding the content and others not. Group work - hard to get children to listen after group work. Not being able to answer questions.

Creating a balance between hands-on activities and control of the running of classroom.

The biggest concern I have is thinking of interactive activities for the children to complete.

With regard to classroom management issues, the students were anxious about setting up and managing group work and investigations, handling equipment and experiments being messy. The issue of keeping children's interest and maintaining their attention during hands-on activities was something that perturbed others: 
The planning involved with carrying out experiments, the groups, resources time management...

Organising group work and making sure that materials are used correctly.

Class management if there are a lot of activities going on at once it is hard to manage each of the groups.

Resources can be hard to get ready in time for the next day ... Some (experiments) can be difficult to organise and manage.

Children abusing group work and messing.

With regard to resources, the main concern students expressed was resource availability and many students feared that the lack of resources in schools would inhibit scientific inquiry in their classrooms. Others were anxious about the management of resources and safety:

Hopefully all the equipment will be in the school.

That there are insufficient resources in schools to teach science.

Safety of students with certain materials and experiments.

\section{Concluding discussion}

This study was conducted with BEd students in one of the larger education colleges in the Republic of Ireland. Considerably higher percentages of this cohort of students had taken biology to Leaving Certificate level than either chemistry or physics. Despite these qualifications, high percentages of the students commenced their second year curriculum science course revealing inaccurate conceptions of biology content knowledge and even higher percentages revealed a lack of understanding of different aspects of physics concepts. While the findings of this study appear to indicate an increase in students' scientific content knowledge in both physics and biology by the end of the course, many still revealed 'inaccurate conceptions' in both disciplines. This is a concern because when these student teachers graduate they will all be obliged to implement the primary science curriculum (DES 1999), which encompasses aspects of physics, chemistry and biology. For the vast majority of these students, this curriculum science course is the only course in science they will engage with prior to commencing teaching. We would question, therefore, whether these student teachers have sufficient understanding of scientific background knowledge to implement the science curriculum in a sufficiently competent manner. Nonetheless, these students were very positive about science and many felt confident about the prospect of teaching science. The findings revealed that in general this student cohort held more positive attitudes about science and the importance of school science and were more confident about teaching science at the end of their curriculum science course. 
The students were asked to reflect on issues they held regarding teaching science. Their responses indicated that they were apprehensive about: their scientific content and pedagogical knowledge; classroom management; and the availability of resources in schools. Higher percentages of students expressed concerns regarding their content and pedagogical knowledge and classroom management skills at the exit stage. While this could be a cause for apprehension, it is important to note, however, that at the time the exit questionnaire was administered these students had two additional teaching practice placements to complete before graduating. It is likely, therefore, that these placements would have helped develop their confidence in teaching science. Furthermore, the responses in the exit questionnaires could indicate that these students were beginning to reflect on their teaching in a more informed, critical and in-depth way. Prior to taking the curriculum science course, these students more than likely would not have had in-depth knowledge regarding different pedagogical approaches to teaching science. The fact that they were reflecting on these approaches at the exit stage, albeit taking account of concerns they held, suggests that the students had at least tried some of these approaches over the course of their teaching practice placements, which is a positive factor in itself. Furthermore, many of these more constructivist inquiry-based approaches that were introduced during the workshops can provide challenges, particularly for the novice teacher, in terms of classroom management and in terms of assessing pupils' conceptual knowledge and skill development. Many of the students' concerns regarding teaching related to the management of group work, insufficient resources and addressing children's 'misconceptions'. These voiced concerns would appear to indicate that this cohort of students had a good understanding of the different approaches to teaching science that were emphasised throughout the curriculum science workshops.

This study has important implications for pre-service teacher education in the Republic of Ireland. On the one hand, the study revealed that the participating preservice primary teachers are by and large confident in their ability to teach science. However, it also highlighted the prevalence of 'alternative conceptions' among preservice teachers regarding a number of science concepts essential in teaching the primary science curriculum. To provide high-quality primary science education, preservice science teachers need to be prepared to teach the science concepts found in the curriculum with confidence and therefore these 'alternative conceptions' must be investigated and addressed in college curriculum science courses.

In response to the issues raised in this study, we put forward the following recommendations for the development of pre-service curriculum science courses.

e Curriculum science courses should be adapted to ensure that pre-service teachers are provided with the opportunity to develop their knowledge and understanding of the key science concepts found in the primary science curriculum. Additional courses to facilitate the development of student teachers' scientific content knowledge should be developed at pre-service and in-service levels. Such courses would facilitate the development of preservice (and practising) teachers' competence in teaching science which would more than likely result in increased confidence in teaching science.

e We would concur with one of the recommendations from the Kellaghan (2009) and Varley, Murphy, and Veale (2008) reports in that we would strongly recommend that specialist science education courses should be developed and 
offered to students over the course of the three years of the BEd degree. While such courses are available to pre-service teachers in Northern Ireland (Waldron et al. 2009), they are not currently available to BEd students in the Republic of Ireland. This would provide a cohort of teachers with a specialism in teaching science, which would serve in providing these teachers with the confidence and expertise to facilitate the development of science teaching within whole-school contexts.

e We would suggest that science departments in the various teacher education colleges could work closely together building on the work developed by the Irish Association for Social, Scientific and Environmental Education (IASSEE) (Waldron et al. 2009). Participation in a community of like-minded colleagues could have a very positive effect on the teaching and learning of primary science in the future.

As science education is now compulsory for all children attending primary school, pre-service teacher science education programmes in the teacher education colleges need to seriously consider the long-term consequences of having teachers entering the profession with the same 'alternative conceptions' as many of their students. Future courses need to address this issue and find ways of overcoming such 'misconceptions' in order that future graduates have sufficient competence and confidence to facilitate successful implementation of the primary science curriculum in Irish primary schools.

\section{Acknowledgements}

We would like to acknowledge the support of the Research Committee, St Patrick's College, Drumondra.

\section{Notes on contributors}

Clíona Murphy is a lecturer in science education in St Patrick's College, Dublin. Currently her principal work focuses on the research, development and delivery of pre-service and postgraduate courses and materials. She has conducted and published research in the area of the Nature of Science within a primary context and in the area of teaching and learning in primary science.

Greg Smith is a lecturer in science education in St Patrick's College, Dublin. He has conducted and published research in the area of professional development of teachers at primary and post-primary level. Research interests include enhancing the teaching and learning of science through effective professional development.

\section{References}

Appleton, K., and I. Kindt. 1999. Why teach primary science? Influences on beginning teachers' practices. International Journal of Science Education 21, no. 2: 155-68.

De Boo, M., and A. Randall. 2001. Celebrating a century of primary science. Hatfield: Association for Science Education.

Department of Education and Science (DES). 1999. Primary school curriculum: Science. Dublin: The Stationery Office.

Department of Education and Science (DES). 2003. Junior Certificate Science syllabus (Ordinary level and higher level). Dublin: The Stationery Office. 
Driver, R. 1983. The pupil as scientist?. Milton Keynes: The Open University Press.

Driver, R., E. Guesne, and A. Tiberghien, eds. 1985. Children's ideas in science. Milton Keynes: Open University Press.

Goodrum, D., M. Hackling, and L. Rennie. 2000. The status and quality of teaching and learning of science in Australian schools. Canberra: Department of Education, Training and Youth Affairs.

Harlen, W., and C. Holroyd. 1997. Primary teachers' understanding of the concepts of science: Impact on confidence and teaching. International Journal of Science Education 19, no. 1: 93105.

Jarvis, T., and A. Pell. 2004. Primary teachers' changing attitudes and cognition during a twoyear science in-service programme and their effect on pupils. International Journal of Science Education 26, no. 14: 1787-811.

Kellaghan, T. 2009. The future of the teacher education continuum in Ireland: Opportunities and challenges. Oideas 54: 14-24.

Kennedy, M. 1998. The relevance of content in in-service teacher education. Paper presented at the annual meeting of the American Educational Research Association, San Francisco.

Kruger, C., and M. Summers. 1988. Primary school teachers' understanding of science concepts. Journal of Education for Teaching 14: 13-7.

Lincoln, Y.S., and E.G. Guba. 1985. Naturalistic inquiry. Newbury Park, CA: Sage.

Loucks-Horsley, S., P.W. Hewson, N. Love, and K.E. Stiles. 1998. Designing professional development for teachers of science and mathematics education. Thousand Oaks, CA: Corwin.

MacDonald, A.L., and A. Sherman. 2007. Pre-service teachers' experiences with a science education module. Journal of Science Teacher Education 18: 525-41.

Matthews, P., and P. McKenna. 1996. Science education: A review of recent research. Studies of Science Education 12, no. 2: 21-36.

McDiarmid, G.W., D.L. Ball, and C. Anderson. 1989. Why staying one chapter ahead doesn't really work: Subject-specific pedagogy. In Knowledge base for the beginning teacher, ed. M.C. Reynolds, 193-205. Elmsford, NY: Pergamon Press.

Murphy, C., P. Neil, and J. Beggs. 2007. Primary science teacher confidence revisited: 10 years on. Educational Research 49, no. 4: 415-30.

National Council for Curriculum and Assessment (NCCA). 2011. Senior cycle science consultation. http://www.ncca.ie.

Office for Standards in Education (OFSTED). 2004. OFSTED subject reports 2002/03: Science in primary schools. London: OFSTED.

Osborne, J., and S. Simon. 1996. Primary science: Past and future directions. Studies in Science Education 26: 99-147.

Rennie, L.J., D. Goodrum, and M. Hackling. 2001. Science teaching and learning in Australian schools: Results of a national study. Research in Science Education 31: 455-98.

Simpson, R.D., and J.S. Oliver. 1990. A summary of the major influences on attitude toward and achievement in science among adolescent students. Science Education 74: 1-18.

Smith, R., and G. Peacock. 1992. Tackling contradictions in teachers' understanding of gravity and air resistance. In Primary science: The challenge of the 1990s, ed. L. Newton. Clevedon: Multilingual Matters.

Summers, M., and C. Kruger. 1992. Research into English primary school teachers' understanding of the concept of energy. Evaluation and Research in Education 6: 95-111.

Varley, J., C. Murphy, and Ó. Veale. 2008. Science in primary schools: Phase 1 final report. http://www.ncca.ie/uploadedfiles/primary/Binder1.pdf (accessed January 21, 2008).

Waldron, W. S. Pike, R. Greenwood, C.M. Murphy, G. O’Connor, A. Dolan, and K. Kerr. 2009. Becoming a teacher. Primary student teachers as learners and teachers of history, geography and science: An all-Ireland study. Standing Conference on Teacher Education North and South (SCoTENS).

Waldron, F., S. Pike, J. Varley, R. Greenwood, and C. Murphy. 2007. Student teachers' prior experiences of history, geography and science: Preliminary findings of an all-Ireland survey. Irish Educational Studies 26, no. 2: 177-94.

Wellcome Trust. 2005. Primary horizons: Starting out in science (summary report). London: Wellcome Trust. http://www.wellcome.ac.uk/assets/wtx026628.pdf. 


\section{Appendix A}

\section{Science Education Questionnaire}

Name:(optional)c.

\section{Section 1}

Background Information

1. Please tick Male $D$ Female $D$

2. Group:

3. Academic Subject:----------

4.Age:

21 and under $D \quad$ over21

\section{Section B}

5. Attitudes towards science

For each statement circle a number that corresponds with how you feel.

N.B. 1 = you strongly AGREE with the statement;

5 = you strongly DISAGREE with the statement

I like science

I liked teaching science on TP

I think science is an important subject for primary children

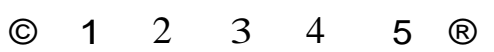

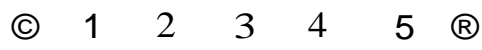

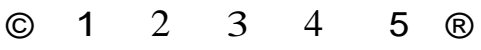


6. Your Ideas about teaching science In primary school.

What do you think makes a good teacher of primary science?

What are your concerns (if any) regarding teaching science?

Are there any particular topics in science that you still think are challenging to teach? Which topics are these?

\section{Section C}

7.Please read the following statements and tick the appropriate boxes.

\begin{tabular}{|l|l|l|}
\hline & True & False \\
\hline (a) Gravity only acts on objects when they are falling & & \\
\hline (b) Friction only acts on moving objects & & \\
\hline $\begin{array}{l}\text { (c) Heavy things fall to the ground quicker than light } \\
\text { things }\end{array}$ & & \\
\hline $\begin{array}{l}\text { (d) Objects which are silting still have no forces } \\
\text { activity on them }\end{array}$ & & \\
\hline (e) The moon is luminous & & \\
\hline $\begin{array}{l}\text { (f) Sound can only travel through air, not solid objects } \\
\text { or liquids }\end{array}$ & & \\
\hline
\end{tabular}

8. Your ideas about science?

Please read the following statements and lick the appropriate boxes. 


\begin{tabular}{|l|l|l|}
\hline & True & False \\
\hline $\begin{array}{l}\text { (a) Less current returns to the battery when it } \\
\text { passes through say a bulb (it is used up) }\end{array}$ & & \\
\hline $\begin{array}{l}\text { (b) Current flows from battery to bulb but not from } \\
\text { bulb back to battery }\end{array}$ & & \\
\hline (c) Gases do not have mass & & \\
\hline (d) If an object is at rest no forces are acting on it & & \\
\hline (f) Wood floats and metal sinks & & \\
\hline (h) All metals are attracted to a magnet & & \\
\hline (l) Heat travels from a cold body to a hot body & & \\
\hline $\begin{array}{l}\text { (k) If two objects have the same temp then they } \\
\text { have the same amount of heal }\end{array}$ & & \\
\hline
\end{tabular}

9. Which of the following Is a plant? Please tick the appropriate box

\begin{tabular}{|l|l|}
\hline & Tick here \\
\hline A tree in the ground & \\
\hline A potato growing in the ground & \\
\hline A daisy growing in the ground & \\
\hline A thistle growing in the ground & \\
\hline
\end{tabular}

10. Which of the following is an animal? Please tick the appropriate box

\begin{tabular}{|l|l|}
\hline & Tick hare \\
\hline A fish in a pond & \\
\hline A dog found around the house & \\
\hline A human being & \\
\hline A common household fly & \\
\hline An elephant & \\
\hline A snake & \\
\hline A spider & \\
\hline
\end{tabular}

